\title{
Differences in Early Vocabulary Development from 18-36-month-old Late Talkers and Typically Developing Toddlers of Matched Age and Expressive Vocabulary Levels
}

\author{
Dongsun Yim, Yoonhee Yang ${ }^{\mathrm{b}}$, Jeongwon Choi ${ }^{\mathrm{a}}$, Jia Han ${ }^{\mathrm{a}}$, Miseon Chae \\ a Department of Communication Disorder, Ewha Womans University, Seoul, Korea \\ ${ }^{b}$ The Special Education Research Institute, Ewha Womans University, Seoul, Korea
}

Correspondence: Dongsun Yim, PhD

Department of Communication Disorders,

Ewha Womans University, 52 Ewhayeodae-gil,

Seodaemun-gu, Seoul 03760, Korea

Tel: $+82-2-3277-6720$

Fax: $+82-2-3277-2122$

E-mail: sunyim@ewha.ac.kr

Received: April 5, 2021

Revised: May 11, 2021

Accepted: May 12, 2021

This work was supported under the framework of international cooperation program managed by the National Research Foundation of Korea (NRF2019K2A9A2A20109497)
Objectives: This study aimed to examine information about two-word combinations of 18-36-month-old toddlers and identify predictors of the two-word combinations in 18-36month-old late talkers, and age-matched, and expressive vocabulary-matched typically developing toddlers. Methods: A total of 1,051 toddlers participated in this study, including 25-36-month-old late-talkers (LT) ( $N=43$ ), typically developing age-matched (AM) toddlers $(\mathrm{N}=847)$, and typically developing expressive vocabulary-matched $(\mathrm{VM})$ toddlers aged 18-24 months $(\mathrm{N}=161)$. The study examines the data collected from Korean MacArthur-Bates Communicative Development Inventories (K M-B CDI; Pae \& Kwak, 2011). The dataset was obtained through the Wordbank website (wordbank.stanford.edu). Results: There were significant differences in the two-word combination utterance for each group. The most frequently represented group of the two-word combinations was the AM group with $12.6 \%$, followed by the LT group with $4.7 \%$, and the VM group with $0.6 \%$. The factor significantly correlated with the two-word combinations was consistently found to be receptive vocabulary in all groups. In addition, the receptive vocabulary factor showed significant explanatory power for the two-word combinations only in the AM group. Conclusion: The LT group showed more two-word combinations yields than the younger VM group, suggesting that the age effect cannot be ignored for two-word combinations. Regarding the production of word classes, the percentage of noun production was the highest out of all the word classes, however the LT group's production was significantly lower than the AM groups. In addition, the LT group lacked the proportion of adjectives compared with the VM group, which suggests that adjectives may be particularly difficult as they are used for describing abstract properties.

Keywords: Korean MacArthur-Bates Communicative Development Inventories (K M-B CDI), 18-36-month-old children, Late talkers, Early vocabulary development, Two-word combinations
아동들은 18-24개월 사이에 어휘폭발기(word spurt)를 경험하 며, 초기에 산출되는 50 개의 어휘는 대부분 일상생활 및 경험을 반 영하는 범주의 어휘들이 주를 이룬다(Bates, Dale, \& Thal, 1995; Bloom et al., 1993; Gentner \& Boroditsky, 2001). 이렇게 아동들의 표현어휘가 50개를 초과할 때쯤 한 단어 산출에 머물렀던 아동의
어휘 산출 능력은 두 단어의 조합으로 발전하게 되는데, 이러한 어 휘능력은 단어 조합(word combinations), 평균 발화 길이(mean length of utterance), 문장의 복잡성(sentence complexity)과 높은 상관관계를 보인다(Bates et al., 1994, 1995). 아동들은 생후 24개월 이 되면 산출할 수 있는 동사의 비율이 증가하면서 약 300 개의 어 
휘를 산출하게 되고, 400 개의 어휘를 습득할 때, 더 높은 비율의 기 능어(예: 접속사, 전치사) 등도 관찰된다(Bates et al., 1994).

아동의 두 단어 조합 출현 여부는 아동의 연령, 어휘량, 초기 단 어 출현 시기, 언어적 입력 등과 유의한 상관관계가 있다. 첫째, 구 문구조 발달은 연령에 따라 더 밀접하게 영향을 받고 '연령 효과 (age effect)'와 정적 상관관계를 보이며 문법습득에도 영향을 미친 다(Braginsky, Yurovsky, Marchman, \& Frank, 2015). 둘째, 단어 조 합은 점점 더 정교해지고 어휘적 지식에 매우 의존적이기 때문에 두 단어 조합에 있어 아동의 어휘량(vocabulary size)은 중요한 역 할을 한다(Bannard, Lieven, \& Tomasello, 2009; Bates et al., 1994; Bates, Bretherton, \& Snyder et al., 1988; Bates \& Goodman, 1999; Braginsky et al., 2015; Tomasello, 2000). 셋째, 초기 단어 출현 시기 및 품사별 산출량과 관련하여 일반 아동과 말 늦은 아동(late talkers, LT)을 비교하면, 말 늦은 아동의 초기 50개 어휘집(lexicon)은 명사가 동사보다 선행되는 형태로 일반 아동과 유사한 분포를 보이 지만, 전체 어휘량의 품사별 명사 비율이 현저히 높고, 동사의 비율 이 더 적다(Conti-Ramsden \& Jones, 1997; Nott, Cowan, Brown, \& Wigglesworth, 2009b). 이후, Nott와 동료들은 두 단어 조합 시 두 집단의 어휘집의 크기는 비슷했지만, 일반 아동의 두 단어 조합이 첫 낱말 산출 이후 더 빠르게 이뤄졌으며, 50 개 이후 100 개 단어 습 득까지 말 늦은 아동보다 더 짧은 기간 동안 이뤼졌다는 것을 밝혔 다(Nott, Cowan, Brown, \& Wigglesworth, 2009a). 이처럼 초기 50 개의 어휘 산출 시기와 초기 품사의 비율이 두 단어 조합에 영향을 줄 수 있는 요인 중 하나라는 것을 알 수 있다. 마지막으로, Bain과 Olswang (1995)은 24-36개월 사이의 말 늦은 아동을 대상으로 단 어 조합을 위한 위계적 단서를 최소 또는 최대로 제공한 결과, 보다 많은 단계별 입력을 받은 집단이 적은 입력을 받았던 집단보다 더 정확하게 두 단어 조합을 표현하였음을 밝히면서 언어적 입력을 통 한 두 단어 조합 구성 타당도를 밝혔다. 또한, 단계별 입력에 대해 큰 반응을 보였던 아동은, 적은 반응을 보였던 아동과 비교하였을 때, 두 단어 조합을 촉진하는데 더 많은 변화를 보였다.

아동의 주요 품사(명사, 동사, 형용사)는 어휘량이 증가하면서 확 장되며, 아동의 어휘량 발달 시기에 따라 각 품사별 산출량 비율도 달라진다(Bates et al., 1994; MacRoy-Higgins, Shafer, Fahey, \& Kaden, 2016). 아동은 이미 자신이 알고 있는 사물의 기능이나 속성과 어휘를 연결하여 구체적으로 어휘를 습득하는데, 주로 동사보다 명사를 먼저 습득하는 것으로 알려져 있다(Gentner, 1982; Markman, 1989; Longobardi et al., 2017). 이는 명사가 동사보다 지각적 으로 명료한 특성과 관련된다(Gentner, 1982). 이러한 의미적 제약 성과 관련하여 Au, Dapretto와 Song (1994)은 한국어를 사용하는
아동은 영어를 사용하는 아동보다 동사가 두드러지게 나타나는 문장에 더 많이 노출되었음에도 한국어 사용 아동과 영어 사용 아 동 모두 명사를 동사보다 빠르게 습득했음을 밝혔다. 또한 Gentner (1982)는 '자연 분할 가설(Natural Partitions hypothesis)'을 통해 명사가 실제 사물과 쉽게 연결되는 반면, 동사는 관계적이고 추상 적인 개념을 담으며, 언어마다 의미적 형태가 다르기 때문에 명사의 산출 비율이 높다고 밝혔다. 따라서 영아가 동사를 습득하기 위해 서는 사건의 구성요소를 개념화하고, 동사를 그 요소들에 연결해 야하기 때문에 많은 명사의 습득이 동사의 습득을 촉진시킬 수 있 다. 따라서, 명사의 습득을 설명하는 '창발적 상관 모델(Emergentist Coalition Model)'은 아동이 동사와 행위를 사건과 연결하기 위 한 언어 정보로 사용될 수 있다(Longobardi, Spataro, Putnick, \& Bornstein, 2017). 이러한 보편적인 명사 습득은 말 늦은 아동에게 도 적용되어 더 낮은 동사 사용의 빈도와 높은 명사 사용의 빈도를 나타냈다(Conti-Ramsden \& Jones, 1997). 즉, 위와 같은 연구를 통 해 아동은 언어발달 시기에 마주하는 다양한 언어적 환경 속에서 다양한 명사들을 습득하게 되고, 이를 활용하여 더 많은 동사를 습득한다는 것을 알 수 있다. 한편, 36 개월 이전 아동은 매우 제한 된 상황 속에서만 새로운 형용사를 사물 속성과 연결할 수 있다 (Hall, Waxman, \& Hurwitz, 1993; Taylor \& Gelman, 1988). Mintz 와 Gleitman (2002)은 두 집단의 아동에게 명료하지 않는 대명사 (one or thing)를 이용해 새로운 형용사를 제시하였을 때 형용사습 득이 어려웠음을 확인하면서 구체적인 참조 정보가 새로운 어휘를 익히는 요인이 되었음을 확인하였다. 이처럼 형용사는 아동이 보지 못하는 속성을 기술하고 수식하고자 하는 명사에 따라 의미가 달 라질 수 있기 때문에 명사에 의존적이며 초기 언어습득 단계에서 명사보다 느리게 습득된다(Cho \& Lee, 2004; Gentner \& Boroditsky, 2001).

일반적으로 한국 아동들은 17 개월에 평균 50 개의 어휘를 산출 하고, 20-21개월 사이에 100 개의 어휘를, 23-24개월 사이에는 어휘 폭발을 경험하는 동시에 하루 3-4개 새로운 어휘를 습득하며, 36개 월경에는 평균 499개의 표현어휘량를 가진다(Chang, 2004). 한국 어를 사용하는 아동들은 약 18 개월부터 두 단어를 결합하기 시작 하고 '행위자+행위' 형식의 전보식 문장(telegraphic sentences)을 만들기 시작한다(Lee, 2009; Lee, Chang, Choi, \& Lee, 2008). 이후 24 개월 이전에 주격조사가 출현하고, 36 개월 이전에는 목적격 조 사를 사용할 수 있게 되며 구문 복잡성이 안정화된다(Kim, 1997; Lee et al., 2008). 이들의 어휘량과 단어 조합의 길이는 일반적으로 동시에 증가하며, 초기 어휘는 대부분 명사와 동사로 구성된다( $\mathrm{Ha}$, Seol, So, \& Pae, 2016). 한국어 어휘 습득에 관한 수많은 연구들에 
의하면, 한국어권 아동들은 영어권 아동들과 다르게 명사보다 동 사를 더 빨리 학습한다는 것을 밝혀내기도 하였다(Kim, McGregor, \& Thompson, 2000; Naigles \& Hoff-Ginsberg, 1998). 한국어는 영 어와는 달리 동사가 문장의 말미에 놓여 지각적으로 더 현저하고 더 자주 사용된다. 그 결과로 한국어에서는 동사가 명사보다 초기 어휘습득에 더 많은 영향을 주어 동사가 명사보다 더 선행하여 습 득되는 '언어 특수성(language specificity)'이 나타난다(Choi \& Gopnik, 1995). 이는 영어권 유아들의 어휘집에서 명사가 가장 많 은 비중을 차지한다는 결과가 나타나는 것과 비교했을 때 한국어 권 유아의 초기 어휘발달 양상이 독특한 양상으로 나타날 수 있음 을 시사한다(Tardif, Shatz, \& Naigles, 1997; Xuan \& Dollaghan, 2013). 한편, 35개월 이전의 한국어를 사용하는 유아들이 가장 많 이 습득한 어휘는 명사로, 언어 보편적으로 명사의 비율이 높다는 연구결과도 나타난다 (Choi, Seo, \& Pae, 2001; Rescorla, Lee, Oh, \& $\mathrm{Kim}, 2013)$. 한국 아동의 경우 문장의 어순과 관련하여 동사에 쉽 게 노출되지만 첫 낱말 이후의 초기 습득 어휘들이 대부분 명사로 '명사 선호성'의 제약을 갖는다고 보는 입장이다(Au et al., 1994; Chang-Song \& Pae, 2003; Pae, 1993).

위와 같이 모든 한국 아동들이 동일한 초기 어휘발달을 보이는 것은 아니지만, 이미 영유아기부터 말 늦은 아동은 또래 일반 아동 에 비해 상징적 제스처에 대한 이해와 표현 또한 크게 다른 양상으 로 나타난다고 보고되기도 한다(Oh, Park, \& Lee, 2015). 말 늦은 아동의 언어 이해력에서의 취약함은 아동이 발달해 나감에 따라 상당한 영향을 미치게 된다. 유아들에게 어휘폭발기가 나타난다고 하는 기간에 해당하는 19 개월 무렵 말 늦은 아동의 표현어휘 수는 50 개 미만이었으며, 두 단어 조합의 표현이 많지 않았다. 결과적으 로 말 늦은 아동은 어휘폭발기를 경험할 수 없었고, 이러한 언어적 결함은 30 개월 미만 말 늦은 아동의 의미관계에도 영향을 미친다 (Choi \& Gopnik, 1995). 또한, 36개월 미만의 말 늦은 아동은 일반 아동에 비해 더 적은 어휘 산출을 보이고, 명사에 비해 동사 학습 이 어려우며, 문법적 요인에 대한 낮은 이해력을 보이기도 한다(Jo, Hwang, \& Choi, 2014; Lee \& Kim, 2003; Lee \& Yim, 2020). 일반 아 동과 비교하여 말 늦은 아동이 갖는 이러한 차이점에도 불구하고 한국어를 사용하는 말 늦은 아동 집단에 대한 두 단어 조합 산출 에 대한 연구는 많이 이루어지지 않았다. 따라서 이들의 두 단어 조 합에 미칠 수 있는 요인을 탐색하고자 말 늦은 아동 집단(late talkers, LT), 생활연령 일치(age matched, AM) 집단, 표현어휘능력 일 치(expressive vocabulary matched, $\mathrm{VM}$ ) 집단으로 나누어 보다 세 부적으로 비교 분석하고자 한다. 또한, Wordbank 데이터베이스에 서 제공하는 빅데이터를 기반으로 하여 데이터 수에서 오는 신뢰
도 또한 확보하고자 한다.

본 연구의 연구 질문은 다음과 같다.

말 늦은 아동 집단(LT), 생활연령 일치 집단(AM), 표현어휘능력 일치 집단(VM) 간 두 단어 조합 패턴에 유의미한 차이가 있는가?

$\mathrm{LT}, \mathrm{AM}, \mathrm{VM}$ 간 품사별(명사, 동사, 형용사) 산출에서 유의미한 차이가 있는가?

각 집단의 두 단어 조합과 유의한 상관관계가 있는 요인은 무엇 인가?

각 집단의 두 단어 조합에 유의미한 영향을 미치는 요인은 무엇 인가?

\section{연구방법}

\section{연구대상}

본 연구는 29 개 언어의 아동 어휘발달 데이터를 포함한 Wordbank 데이터베이스(http://wordbank.stanford.edu)에 기록되어 있는 유아용 한국판 맥아더-베이츠 의사소통발달 평가(Korean MacArthur-Bates Communicative Development Inventories, K M-B CDI; Pae \& Kwak, 2011) 결과를 토대로 대상자를 선정하였다. 만 25-36개 월의 말 늦은 아동(LT) 43 명, LT 집단과 생활연령을 일치시킨 일반 아동(AM) 847명, 그리고 LT 집단과 표현어휘능력을 일치시킨 18-24 개월의 일반 아동 $(\mathrm{VM}) 161$ 명, 총 1,051 명을 대상으로 하였다.

비교 집단의 연령 통제가 잘 이루어졌는지 살펴보기 위해 일원 분산분석(One-way ANOVA)을 실시한 결과, LT 아동 집단 평균 개 월 수는 28.53개월( $\mathrm{SD}=3.12), \mathrm{AM}$ 아동 집단 평균 개월 수는 29.02 개월 $(\mathrm{SD}=2.73)$ 로 생활연령이 유사하였으며, $\mathrm{VM}$ 아동 집단의 평 균 개월 수는 20.20개월 $(\mathrm{SD}=1.79)$ 로 $\mathrm{LT}$ 아동 집단과 $\mathrm{AM}$ 아동 집 단의 평균 개월 수와 비교하여 차이가 있었다. 즉, $\mathrm{LT}, \mathrm{AM}$ 아동 집 단은 $\mathrm{VM}$ 아동 집단보다 생활연령이 높아 세 집단 간 연령 통제가 잘 되었다고 할 수 있다.

세 집단 간 표현어휘 및 수용어휘의 차이가 유의하였다. LT 집단 의 표현어휘량의 평균은 20.84 개(SD = 15.13)로 $\mathrm{AM}$ 집단의 표현어 휘량의 평균 390.91 개( $\mathrm{SD}=160.86)$ 보다 적고, $\mathrm{VM}$ 집단의 표현어휘 량의 평균 22.48개(SD = 13.67) 또한 $\mathrm{AM}$ 집단의 표현어휘보다 적었 다. LT 집단의 수용어휘량의 평균은 202.95개(SD=221.50)로 $\mathrm{AM}$ 집단의 수용어휘의 수의 평균인 413.55 개 $(\mathrm{SD}=154.64)$ 보다 적고, $\mathrm{VM}$ 집단의 수용어휘량의 평균 51.14 개 $(\mathrm{SD}=83.13)$ 보다 유의하게 많았다. VM 집단에 비해서는 LT 집단의 수용어휘 수의 평균이 유 의하게 더 많았다. 세부 결과를 Table 1 에 제시하였다. 
Table 1. Participants' characteristics

\begin{tabular}{|c|c|c|c|c|c|}
\hline Variables & $\mathrm{LT}(\mathrm{N}=43)$ & $\mathrm{AM}(\mathrm{N}=847)$ & VM $(N=161)$ & $F$ & Post-hoc \\
\hline Age & $28.53(3.12)$ & $29.02(2.73)$ & $20.20(1.79)$ & $740.875^{* *}$ & $\begin{array}{l}\mathrm{LT}>\mathrm{VM} \\
\mathrm{AM}>\mathrm{VM}\end{array}$ \\
\hline Word production ${ }^{\mathrm{a}}$ & $20.84(15.13)$ & 390.91 (160.86) & $22.48(13.67)$ & $533.672^{* *}$ & $\begin{array}{l}\mathrm{LT}<\mathrm{AM} \\
\mathrm{VM}<\mathrm{AM}\end{array}$ \\
\hline Word comprehension ${ }^{\mathrm{a}}$ & $202.95(221.50)$ & $413.55(154.64)$ & $51.14(83.13)$ & $400.487^{* *}$ & $\begin{array}{l}\mathrm{LT}<\mathrm{AM} \\
\mathrm{VM}<\mathrm{AM} \\
\mathrm{VM}<<\mathrm{LT}\end{array}$ \\
\hline
\end{tabular}

Values are presented as mean (SDs).

$\mathrm{LT}=$ Late talkers; $\mathrm{AM}=$ Age-matched typically developing toddlers; VM= Expressive vocabulary-matched typically developing toddlers.

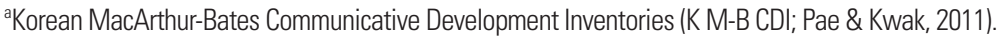

${ }^{* *} p<.001$

\section{연구변인}

연구대상

말늦은아동

본 연구에서 말 늦은 아동(LT)은 25-36개월 아동 중 McArthurBates Communication Development Inventory (M-B CDI; Fenson et al., 1993) 전문가 지침서의 규준에 따라 유아용 K M-B CDI에서 각 아동의 월령, 성별을 기준으로 i) 총 산출 어휘가 백분위 $10 \%$ ile 이하이고, ii) 표현어휘가 50 개 미만인 아동으로 정의하였다(Robertson \& Ellis-Weismer, 1999).

생활 연령을 일치시킨 일반 아동

본 연구에서 LT와 생활 연령을 일치시킨 일반 아동(AM)은 25-36 개월 아동 중 M-B CDI 지침서에 따라 유아용 K M-B CDI에서 i) 총 산출 어휘가 백분위 $10 \%$ ile 이상이고, ii) 표현어휘가 50 개 이상 인 아동으로 정의하였다(Robertson \& Ellis-Weismer, 1999).

표현어휘능력을 일치시킨 일반아동

본 연구에서 LT와 표현어휘를 일치시킨 일반 아동(VM)은 M-B $\mathrm{CDI}$ 지침서에 따라 유아용 K M-B CDI에서 i) 총 표현어휘 수가 50 개 미만이나, ii) 백분위 $10 \%$ ile 이상으로 정상 범주에 속하는 18-24 개월 아동으로 정의하였다.

\section{연령}

본 연구에서는 연령을 세 집단(LT, AM, VM)으로 나누어 비교 분석하였다. LT 집단의 경우 25-36개월 아동 43명, $\mathrm{AM}$ 집단의 경우 $25-36$ 개월 847 명, $\mathrm{VM}$ 집단의 경우 $18-24$ 개월 161 명이 포함되었다.

\section{표현어휘와 수용어휘}

본 연구에서는 Wordbank (wordbank.stanford.edu) 데이터베이
스의 한국어 사용 아동의 데이터를 기반으로 하며, Wordbank에 기 록되어 있는 표준화된 부모 보고 설문지인 '맥아더-베이츠 의사소 통발달 평가(Korean Macarthur-Bates Communicative Development Inventories, K M-B CDI)'의 점수를 통해 표현어휘와 수용어 휘를 측정하였다. 표현어휘는 아동이 해당 어휘의 의미를 이해하고 사용하는 것을 말하며, 단순 모방하는 것으로는 표현어휘에 해당하 지 않는다. 수용어휘는 그 어휘의 의미를 이해하는 것을 말한다.

\section{품사별(명사, 동사, 형용사) 산출 어휘}

각 아동의 표현어휘 내의 품사별 산출 비율이 두 단어 조합 산출 에 영향을 미치는지 살펴보기 위해 전체 품사 중 내용어에 해당하 는 명사, 동사, 형용사의 산출 어휘를 분리하여 살펴보았다 (Bates et al., 1994). 품사별 산출 어휘는 K M-B CDI 검사지를 통해 언어병 리학 전공 석사과정 학생 4 인, 박사과정 학생 1 인의 검토를 통해 명 사 318 개(2. 탈 것, 3. 장난감 및 문구류, 4. 동물, 5 , 옷, 6. 가구 및 방 안, 7. 음식, 8. 신체부위, 9. 가정용품, 10. 외부사물, 12. 장소, 14. 사 람), 동사 150 개(16. 동사), 형용사 52 개(17. 형용사)로 선정되었다.

\section{두 단어 조합}

$\mathrm{KM}-\mathrm{B} \mathrm{CDI}$ 검사지 문항 중 문법과 문장 부분의 '가. 문장표현 정 도'의 '1. 우리 아이가 낱말을 붙여서 말합니까? (예: “이거 이뻐”, “물 줘”)' 문항에서 안 함(0), 가끔(1), 종종(2)의 3점 척도 중 체크하 도록 하여 단어 조합의 양상을 살펴볼 수 있도록 하였다.

\section{자료분석 및 결과처리}

세 집단(LT, AM, VM)의 두 단어 조합 산출 양상을 비교하기 위 해 카이제곱 검정(chi-square test)을 사용하였고, 세 집단(LT, AM, $\mathrm{VM}$ )의 표현어휘 내 품사별(동사, 명사, 형용사) 산출 비율의 차이 를 알아보기 위해 다변량분석(multivariate analysis)을 사용하였으 
며, 두 단어 조합과 유의한 상관이 있는 요인을 알아보기 위해 피어 슨의 적률상관계수(Pearson's Correlation Coefficient), 그리고 두 단어 조합에 유의하게 기여하는 변인을 알아보기 위해 로지스틱 회 귀분석(logistic regression)을 사용하였다. 본 연구의 모든 통계분 석은 SPSS ver. 25 (SPSS Inc, Chicago, IL, USA)를 사용하였다.

\section{연구결과}

\section{세 집단(LT, AM, VM)의 두 단어 조합 산출의 차이}

각 집단에 대한 두 단어 조합 산출에는 통계적으로 유의한 차이 가 있었다 $\left(\chi^{2}=27.177, p=.000\right)$. 두 단어 조합이 가장 자주(2점) 나 타나는 집단은 $\mathrm{AM}$ 집단(12.6\%), 그다음으로는 LT 집단(4.7\%), 그 리고 VM 집단(.6\%) 순으로 AM 집단이 가장 높은 비율로 나타났 다. 또한, 두 단어 조합이 종종(1점) 나타나는 집단으로는 LT 집단 (9.3\%)이 가장 높은 비율로 나타났으며, 그다음으로 $\mathrm{AM}$ 집단과

Table 2. Two-word combinations by subgroups

\begin{tabular}{lcccc}
\hline $\begin{array}{l}\text { Two words } \\
\text { combinations }\end{array}$ & LT (N=43) & AM (N=847) & VM (N=161) & Total \\
\hline 0 (none) & $37(86.0 \%)$ & $713(84.3 \%)$ & $155(96.3 \%)$ & $905(86.2 \%)$ \\
1 (sometimes) & $4(9.3 \%)$ & $26(3.1 \%)$ & $5(3.1 \%)$ & $35(3.3 \%)$ \\
2 (often) & $2(4.7 \%)$ & $107(12.6 \%)$ & $1(.6 \%)$ & $110(10.5 \%)$ \\
\hline
\end{tabular}

Values are presented as mean (SE).

$\mathrm{LT}=$ Late talkers; $\mathrm{AM}=$ Age-matched typically developing toddlers; $\mathrm{VM}=$ Expressive vocabulary-matched typically developing toddlers.
$\mathrm{VM}$ 집단이었다(3.1\%). 두 단어 조합이 아직 나타나지 않은(0점) 집 단은, VM 집단(96.3\%)이 가장 높은 비율로 나타났고, 그다음으로 $\mathrm{LT}$ 집단(86.0\%), $\mathrm{AM}$ 집단(84.3\%) 순이었다. 이에 대한 결과를 $\mathrm{Ta}-$ ble 2, Figure 1에 제시하였다.

\section{세 집단(LT, AM, VM)의 표현어휘 내 품사별(명사, 동사, 형용사) 단어 산출 비율의 차이}

세 집단(LT, AM, VM)의 표현어휘 내 품사별(명사, 동사, 형용사) 단어 산출 비율의 양상을 살펴보았다. 즉, 각 품사별 단어산출 개수 를 아동의 총 표현어휘 수로 나누어 100 을 곱한 값으로, 아동의 표

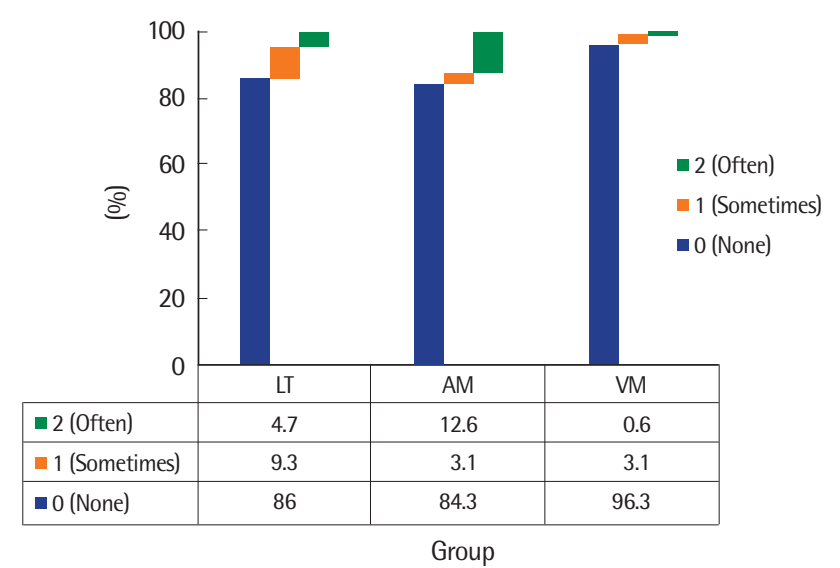

Figure 1. Two-word combination aspects in each group.

$\mathrm{LT}=$ Late talkers; $\mathrm{AM}=$ Age-matched typically developing toddlers; $\mathrm{VM}=$ Expressive vocabulary-matched typically developing toddlers.

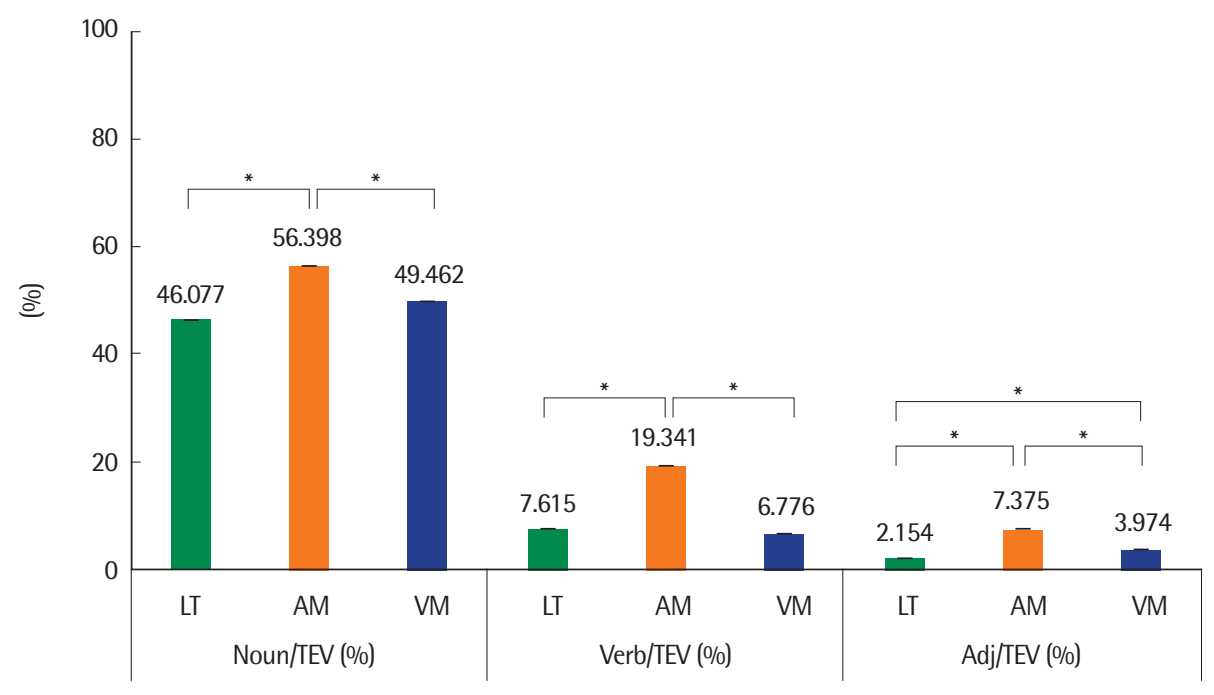

Figure 2. Expressive vocabulary by word class (noun, verb, adjective) in each group.

$\mathrm{LT}=$ Late talkers; $\mathrm{AM}=$ Age-matched typically developing toddlers; VM=Expressive vocabulary-matched typically developing toddlers; TEV=Total expressive vocabulary.

${ }^{*} p<.05$. 
Table 3. Correlation table by subgroups

\begin{tabular}{lcccccc}
\hline & Age & $\begin{array}{c}\text { Expressive } \\
\text { vocabulary }\end{array}$ & $\begin{array}{c}\text { Receptive } \\
\text { vocabulary }\end{array}$ & Noun & Verb & Adjective \\
\hline 2WC_LT & .164 & .262 & $.485^{* *}$ & .274 & .264 & -.026 \\
2WC_AM & .002 & -.006 & $.540^{* *}$ & -.058 & .027 & .022 \\
2WC_VM & .069 & .111 & $.552^{* *}$ & .113 & .026 & -.018 \\
\hline
\end{tabular}

$2 \mathrm{WC}=$ Two-word combination; $\mathrm{LT}=$ Late talkers; $\mathrm{AM}=$ Age-matched typically developing toddlers; VM=Expressive vocabulary-matched typically developing toddlers. ${ }^{* *} p<.01$.

현어휘 내 품사별 산출 비율을 알 수 있다. 그 결과, 모든 품사에서 집단 간 차이가 유의하였다. 즉, 명사 $\left(F_{(2,1039)}=36.661, p=.001\right)$, 동 사 $\left(F_{(2,1039)}=252.385, p=.000\right)$, 형용사 $\left(F_{(2,1039)}=90.804, p=.000\right)$ 모 두에서 집단 간 유의한 산출 차이를 보였다. 세부적으로 어떤 집단 간 차이가 유의하였는지 살펴보기 위해 Bonferroni 사후분석(posthoc)을 실시한 결과, 각 집단 아동의 표현어휘 내 명사, 동사의 비율 은 $\mathrm{AM}$ 집단과 $\mathrm{LT}$ 집단, $\mathrm{AM}$ 집단과 $\mathrm{VM}$ 집단의 차이가 유의하였으 며 $(p<.05), \mathrm{LT}$ 집단과 $\mathrm{VM}$ 집단의 차이는 유의하지 않았다 $(p>.05)$. 한편, 각 집단 아동의 표현어휘 내 형용사의 비율은 $\mathrm{AM}$ 집단과 $\mathrm{LT}$ 집단, $\mathrm{AM}$ 집단과 $\mathrm{VM}$ 집단, 그리고 $\mathrm{LT}$ 집단과 $\mathrm{VM}$ 집단의 차이가 모두 유의하였다 $(p<.05)$. 즉, AM, VM, LT의 순으로 LT 집단의 표 현어휘 산출에서 형용사 비율은 유의하게 가장 낮은 것으로 나타 났다. 이에 대한 결과를 Figure 2에 제시하였다.

\section{세 집단(LT, AM, VM)에서의 두 단어 조합과 유의한 상관요인}

세 집단 각각에서 두 단어 조합과 연령, 표현어휘 점수, 수용어휘 점수, 명사 산출, 동사 산출, 형용사 산출 점수 간 유의한 상관요인 이 있는지 확인하였다. 그 결과, $\mathrm{LT}, \mathrm{AM}, \mathrm{VM}$ 집단 모두에서 두 단 어 조합과 수용어휘 점수 간 상관관계가 유의한 것으로 나타났다 (LT: $r=.485, p=.001$; AM: $r=.540, p=.000$; VM: $r=.552, p=.000$ ). 이에 대한 결과를 Table 3 에 제시하였다.

\section{세 집단(LT, AM, VM)에서의 두 단어 조합에 대한 예측요인}

세 집단 각각에서 두 단어 조합에 대한 예측요인을 확인하고자 6 가지 독립변수인 연령, 표현어휘 점수, 수용어휘 점수, 명사 산출, 동 사 산출, 형용사 산출 점수를 입력하여 로지스틱 회귀분석을 실시 하였다. 그 결과, $\mathrm{LT}, \mathrm{VM}$ 집단에서는 모형 적합의 타당성이 불확실 한 것으로 나타났으며, AM 집단에서는 표현어휘력은 두 단어 산출 조합이 나타나지 않음(0점)을 기준값으로 하였을 때, 종종(1점)에 서는 수용어휘 점수(Wald $=79.139, p=.000$ )가 두 단어 조합에 대 한 가장 큰 설명력을 보였고, 자주(2점)에서는 표현어휘 점수(Wald= $4.190, p=.041)$, 수용어휘 점수(Wald $=90.716, p=.000)$, 명사 (Wald $=$
Table 4. Logistic regression analysis for predicting two-words combination in AM group

\begin{tabular}{lrrrrrrrr}
\hline \multirow{2}{*}{ Factors } & \multicolumn{3}{c}{ 2WC (sometimes=1) } & & \multicolumn{3}{c}{ 2WC (often=2) } \\
\cline { 2 - 3 } \cline { 8 - 9 } & $\beta$ & Wald & $p$-value & & $\beta$ & Wald & $p$-value \\
\hline Age & -.111 & 1.054 & .305 & & -.049 & 1.075 & .300 \\
Production & .007 & .036 & .850 & & .031 & 4.190 & $.041^{*}$ \\
Comprehension & .073 & 79.139 & $.000^{* *}$ & & .076 & 90.716 & $.000^{* *}$ \\
Noun & -.031 & .608 & .436 & & -.037 & 4.750 & $.029^{*}$ \\
Verb & .008 & .031 & .859 & & -.011 & .256 & .613 \\
Adjective & -.025 & .085 & .771 & & -.050 & 1.455 & .228 \\
\hline
\end{tabular}

$2 \mathrm{WC}=$ Two-word combination.

${ }^{*} p<.05,{ }^{* *} p<.01$.

$4.750, p=.029)$ 가 두 단어 조합에 대한 가장 큰 설명력을 보였다 (Table 4).

\section{논의 및 결론}

본 연구에서는 말 늦은 아동 집단(LT, Late talkers), 생활연령 일 치 집단(AM, Age matched group), 표현어휘능력 일치 집단(VM, Expressive vocabulary matched group) 간 두 단어 조합 패턴에 유 의미한 차이가 있는지, 세 집단 간 품사별(명사, 동사, 형용사) 산출 에서 유의미한 차이가 있는지, 두 단어 조합과 유의한 상관이 있는 요인, 두 단어 조합에 유의미한 영향을 미치는 요인은 무엇인지 확 인해보고자 하였다. 그 결과에 대한 논의는 다음과 같다.

첫째, $\mathrm{LT}$ 집단은 $\mathrm{AM}$ 집단보다 유의하게 더 적은 두 단어 조합 산 출을 보여주었는데, 이는 LT 집단이 일반적으로 연령이 일치하고 전형적으로 발전하는 또래들보다 더 적은 두 단어 조합 산출 패턴 을 만들어 낸다는 것을 보여주었다. 수많은 선행 연구에서는 말 늦 은 아동(LT)을 연령이 일치하는 또래보다 단어 조합이 늦다고 보 고했으며, 또한 어휘량(vocabulary size)과 단어 조합 능력이 부족 한 집단으로 분류하였다(Klee et al., 1998; Preston et al., 2010; Rescorla, 1989; Rescorla \& Achenbach, 2002; Rescorla \& Alley, 2001; Rescorla, Hadicke-Wiley, \& Escarce, 1993; Zubrick, Taylor, Rice, \& Slegers, 2007). LT 집단과 VM 집단은 표현어휘 산출 수준이 매우 유사하지만 LT 집단은 어린 연령의 VM 집단보다는 유의하게 높은 두 단어 조합 산출을 보여, 구문구조 발달이 연령에 밀접하게 영향 을 받고 연령 효과(age effect)와 정적 상관관계를 보인다고 한 선행 연구의 결과와 같이 두 단어 조합에서도 연령 효과(age effect)를 무 시할 수 없음을 시사하였다(Braginsky et al., 2015). 따라서, 아동들 의 연령 발달이 단순한 어휘적 성장을 넘어 구문적 습득에도 영향 을 미친다는 것을 증명하였다. 
둘째, 세 집단(LT, AM, VM)의 표현어휘 내 품사별(명사, 동사, 형 용사) 단어 산출 비율과 관련해서는 LT 집단과 VM 집단의 표현어 휘능력이 일치하였더라도 LT 집단은 VM 집단에 비해 유의하게 낮 은 비율의 형용사를 산출한 것으로 나타났다. LT 집단은 더 어린 연 령의 VM 집단보다 자신이 표현 가능한 표현어휘 목록 내 형용사의 비율이 부족하였는데 형용사는 명사를 수식하며 수식하는 명사 에 따라 의미가 달라질 수 있기 때문에 명사에 의존적이다(Cho \& Lee, 2004). 어린 아동들은 매우 제한된 상황 속에서만 새로운 형용 사와 사물 속성을 연결할 수 있는데, 특히 아동이 대상의 명칭을 이 미 알고 있을 때 또 다른 새로운 어휘가 제시되면 비로소 대상의 명 칭이 아닌 대상의 속성으로 추론할 수 있게 된다. 또한 수식어인 형 용사는 추상적인 속성을 기술함으로써 초기 언어습득 단계에서 명 사에 비해 상대적으로 느리게 습득되며 LT 아동들에게는 더욱 어 려울 수 있다(Gentner \& Boroditsky, 2001). 표현어휘 내 명사, 동사 의 비율은 $\mathrm{AM}$ 집단이 가장 높고, $\mathrm{LT}$ 집단과 $\mathrm{VM}$ 집단은 비슷한 산 출 비율을 보였다. 선행연구에 따르면, 더 일찍 말하기 시작하는 아 동은 명사와 동사의 비율도 높고, 문법적 기능어도 더 많이 출현한 다고 보고되는데, AM 집단 역시 LT 집단에 비해 상대적으로 더 이 른 시기에 말을 시작한 집단으로 총 표현어휘 내 명사, 동사 등 주요 품사의 비율이 LT 집단에 비해 높고 이것은 또한 추후 문법적 발달 에도 중요한 역할을 할 수 있다(Hadley, Rispoli, \& Hsu, 2016; Mc-

Gregor, Sheng, \& Smith, 2005). 한편, MacRoy-Higgins 등(2016)의 연구에서는 명사 산출 비율은 공통적으로 전체 품사 중 가장 높았 지만 LT 집단의 명사 산출 비율은 VM과 $\mathrm{AM}$ 집단에 비해 현저히 낮았다. 이와 관련해 MacRoy-Higgins와 연구진 (2016)은 명사 산 출 비율이 어휘폭발기(vocabulary spurt)와 밀접한 관련이 있다고 제안했다(Rescorla, Mirak, \& Singh, 2000). 본 연구에서는 형용사 를 제외한 명사, 동사에서는 LT와 VM의 비율 차이는 없었으나, 명 사의 경우 기술 통계상으로 LT 집단이 VM 집단에 비해 밑도는 것 으로 나타난다. 이는 VM 집단이 가까운 미래에 어휘폭발기를 경 험할 수 있음을 나타내지만 LT 집단은 명사 산출 비율이 상대적으 로 낮아 어휘습득의 효율성을 나타내는 지표인 어휘폭발기를 경험 할 가능성이 낮다는 점을 시사한다.

셋째, 세 집단(LT, AM, VM) 모두에서 두 단어 조합과 가장 유의 한 상관관계가 있었던 요인은 ‘수용어휘’였다. 언어 발달 초기에 영 유아의 이해어휘는 표현어휘 점수를 크게 웃돌다가 만 2세 무렵 표 현어휘능력이 빠른 성장을 하면서 차이가 줄어들지만 여전히 이해 어휘의 수가 높은 것으로 나타나는데 이는 추후 두 단어 조합을 위 한 토대가 될 수 있다(Kim \& Lee, 2009). 또한, Lee (2009)의 연구에 서 25-36개월 아동의 수용언어에 대해 두 단어 조합 요인이 '단어+
몸짓'과 더불어 유의한 예측력을 지니는 것으로 보고되었다. LT 아 동의 어휘에서 파생된 의미적 네트워크는 다른 일반 아동 집단에 비해 더 적은 연결성, 더 작게 생성된 구조를 지니는 것으로 나타남 에도 불구하고 본 연구에서 LT 아동의 수용어휘가 두 단어 조합과 유의한 관련성이 있는 것으로 나타나 만 36개월 이전의 영유아의 두 단어 조합, 초기 구문발달에 있어서 비교적 일관적인 수용어휘 의 중요성을 시사한다고 볼 수 있다(Beckage, Smith, \& Hills, 2011).

넷째, 일반 아동 $\mathrm{AM}$ 집단에서는 두 단어 조합이 종종(1점) 일어 날 때 수용어휘 점수가, 그리고 자주(2점) 일어날 때 표현어휘 점수, 수용어휘 점수, 명사가 두 단어 조합에 대한 가장 큰 예측요인으로 강한 설명력을 보였다. 이 결과는 아동의 어휘의 크기(vocabulary size)는 단어 조합을 위해 필요한 구문론 습득에 대한 강력한 예측 변수인 것을 밝혀낸 Bates 등(1988) 연구 결과와 동일하다. 이와 같 이 구문론은 어휘적 지식에 매우 의존적이며(Bannard et al., 2009;

Bates et al., 1994; Bates \& Goodman, 1999; Braginsky et al., 2015) 정교하고 밀도 높은 어휘를 습득하는 과정에서 점차 추상화되며 발전한다(Tomasello, 2000). 또한, Gentner (1982)의 자연 분할 가 설(Natural Partitions hypothesis)에 따르면, 아동의 어휘집에 포함 되어 있는 명사가 새로운 동사의 습득을 촉진하며 창발적 상관 모 델(Emergentist Coalition Model)은 위와같이 습득한 명사와 동사 의 사용을 돕는다고 보고하고 있어 본 연구결과를 뒷받침한다. Bates 와 연구진(1994)은 어휘폭발기 이후 동사의 비율이 증가했음을 확 인했지만, 명사는 아이들의 총 어휘수가 100-200개에 도달했을 때 에도 지속적으로 가장 큰 비중을 차지하고 있고, 이러한 어휘의 축 적이 구문 산출을 이끌 수 있다 (McGregor et al., 2005).

본 연구의 제한점은 25-36개월 아동의 두 단어 조합 및 습득한 품사별 어휘들을 살펴보기 위해 $\mathrm{KM}-\mathrm{B} \mathrm{CDI}$ 의 어휘들만 분석에 이 용했다는 점이다. K M-B CDI의 어휘들은 아동들의 어휘 사용력을 평가할 수 있도록 검증된 도구이지만 각 아동들의 언어 환경에 따 라 달라지는 어휘들이 제한적으로 평가되었을 수도 있기 때문에, 추후 연구에서는 자발화 분석 등을 통한 다양한 언어적 환경의 단 어들을 분석에 포함해 살펴보는 것도 필요할 것이다.

\section{REFERENCES}

Au, T., Dapretto, M., \& Song, Y. (1994). Input vs constraints: early word acquisition in Korean and English. Journal of Memory and Language, 33(5), 567-582.

Bain, B. A., \& Olswang, L. B. (1995). Examining readiness for learning twoword utterances by children with specific expressive language impairment: 
dynamic assessment validation. American Journal of Speech-Language Pathology, 4(1), 81-91.

Bannard, C., Lieven, E., \& Tomasello, M. (2009). Modeling children's early grammatical knowledge. Proceedings of the National Academy of Sciences, 106(41), 17284-17289.

Bates, E., Bretherton, I., \& Snyder, L. (1988). From first words to grammar: individual differences and dissociable mechanisms. New York: Cambridge University Press.

Bates, E., Dale, P. S., \& Thal, D. (1995). Individual differences and their implications for theories of language development. In P. Fletcher \& B. MacWhinney (Eds.), Handbook of child language (pp. 96-151). Oxford: Blackwell.

Bates, E., \& Goodman, J. (1999). On the emergence of grammar from the lexicon. In B. MacWhinney (Ed.). The emergence of language (pp. 29-79). Mahwah, NJ: Lawrence Erlbaum.

Bates, E., Marchman, V., Thal, D., Fenson, L., Dale, P., Reznick, J., ..., \& Hartung, J. (1994). Developmental and stylistic variation in the composition of early vocabulary. Journal of Child Language, 21(1), 85-123.

Beckage, N., Smith, L., \& Hills, T. (2011). Small worlds and semantic network growth in typical and late talkers. PloS One, 6(5), e19348.

Bloom, L., Tinker, E., \& Margulis, C. (1993). The words children learn: evidence against a noun bias in early vocabularies. Cognitive Development, $8(4), 431-450$.

Braginsky, M., Yurovsky, D., Marchman, V. A., \& Frank, M. C. (2015). Developmental changes in the relationship between grammar and the lexicon. In D. C. Noelle, R. Dale, A. S.Warlaumont, J. Yoshimi, T. Matlock, C. D. Jennings, \& P. P. Maglio (Eds.), Proceedings of the 37th Annual Meeting of the Cognitive Science Society (pp. 256-261). Austin, TX: Cognitive Science Society.

Chang, Y. (2004). Early lexical development of Korean infants: 18-36 Months. The Korean Journal of Developmental Psychology, 17(4), 91-106.

Chang-Song, Y., \& Pae, S. (2003). Noun versus verb bias revisited. Korean Society of Speech Sciences, 10(1), 131-141.

Cho, Y., \& Lee, H. (2004). The role of comparison and lexical information in Korean child's acquisition of novel adjectives. The Korean Journal of Developmental Psychology, 17(2), 197-212.

Choi, E., Seo, S., \& Pae, S. (2001). A study of expressive vocabulary of Korean children at $1 ; 1-2 ; 7$ years of age. Korean Journal of Communication \& Disorders, 6(1), 1-16.

Choi, S., \& Gopnik, A. (1995). Early acquisition of verbs in Korean: a crosslinguistic study. Journal of Child Language, 22(3), 497-529.
Conti-Ramsden, G., \& Jones, M. (1997). Verb use in specific language impairment. Journal of Speech, Language, and Hearing Research, 40(6), 12981313.

Fenson, L., Dale, P., Reznick, J., Thal, D., Bates, E., Hartung, J., ..., \& Reilly, J. (1993). The MacArthur Communicative Development Inventories: user's guide and technical manual. San Diego, CA: Singular Publishing Group.

Gentner, D. (1982). Why are nouns learned before verbs: linguistic relativity versus natural partitioning. In S. Kuzaj (Ed.), Language development: Vol. 2. Language, cognition, and culture (pp. 301-334). Hillsdale, NJ: Erlbaum.

Gentner, D., \& Boroditsky, L. (2001). Individuation, relativity and early word learning. In M. Bowerman \& S. Levinson (Eds.), Language acquisition and conceptual development (pp. 215-256). Cambridge, UK: Cambridge University Press.

Ha, S., Seol, A., So, J., \& Pae, S. (2016). Speech and language development patterns of Korean two-year-old children from analysis of spontaneous utterances. Communication Sciences \& Disorders, 21(1), 47-59.

Hadley, P. A., Rispoli, M., \& Hsu, N. (2016). Toddlers' verb lexicon diversity and grammatical outcomes. Language, Speech, and Hearing Services in Schools, 47(1), 44-58.

Hall, D. G., Waxman, S. R., \& Hurwitz, W. M. (1993). How two- and fouryear-old children interpret adjectives and count nouns. Child Development, 64(6), 1651-1664.

Jo, S., Hwang, M., \& Choi, K. (2014). Sentence interpretation strategies by typically developing and late-talking Korean toddlers. Phonetics and Speech Sciences, 6(3), 13-21.

Kim, Y. J. (1997). The acquisition of Korean. In D. I. Solbin (Ed.), The crosslinguistic study of language acquisition (Vol. 4, p. 335-443), Hillsdale, NJ: Erlbaum.

Kim, M., McGregor, K., \& Thompson, C. (2000). Early lexical development in English-and Korean-speaking children: language-general and languagespecific patterns. Journal of Child Language, 27(2), 225-254.

Kim, M., \& Lee, K. (2009). Relationships between toddler-teacher joint attention and toddlers' vocabularies. Korean Journal of Child Studies, 30(5), 155 165.

Klee, T., Carson, D. K., Gavin, W. J., Hall, L., Kent, A., \& Reece, S. (1998). Concurrent and predictive validity of an early language screening program. Journal of Speech, Language, and Hearing Research, 41(3), 627-641.

Lee, H. (2009). A longitudinal study of emergence of the first verb and maternal linguistic inputs. Journal of Speech-Language \& Hearing Disorders, 18(18), 1-15. 
Lee, H., Chang, Y., Choi, Y., \& Lee, S. (2008). Acquisition of grammatical function words in Korean Children. Korean Journal of Communication \& Disorders, 13(2), 159-173.

Lee, M., \& Yim, D. (2020). A 5-month follow-up study on predictors of expressive vocabulary development in late talkers. Special Education, 19(1), $5-28$.

Lee, Y., \& Kim, Y. (2003). Word production (noun and verb) in children with specific language impairment. Korean Journal of Communication \& Disorders, 8(1), 1-19.

Longobardi, E., Spataro, P., Putnick, D., \& Bornstein, M. (2017). Do early noun and verb production predict later verb and noun production? Theoretical implications. Journal of Child Language, 44(2), 480-495.

MacRoy-Higgins, M., Shafer, V., Fahey, K., \& Kaden, E. (2016). Vocabulary of toddlers who are late talkers. Journal of Early Intervention, 38(2), 118129.

Markman, E. M. (1989). Categorization and naming in children: Problems of induction. The MIT Press.

McGregor, K. K., Sheng, L. I., \& Smith, B. (2005). The precocious two-yearold: Status of the lexicon and links to the grammar. Journal of Child Language, 32(3), 563-585.

Mintz, T. H., \& Gleitman, L. R. (2002). Adjectives really do modify nouns: the incremental and restricted nature of early adjective acquisition. Cognition, 84(3), 267-293.

Naigles, L., \& Hoff-Ginsberg, E. (1998). Why are some verbs learned before other verbs? Effects of input frequency and structure on children's early verb use. Journal of Child Language, 25(1), 95-120.

Nott, P., Cowan, R., Brown, P. M., \& Wigglesworth, G. (2009a). Early language development in children with profound hearing loss fitted with a device at a young age: Part $\mathrm{I}-$ The time period taken to acquire first words and first word combinations. Ear and Hearing, 30(5), 526-540.

Nott, P., Cowan, R., Brown, P. M., \& Wigglesworth, G. (2009b). Early language development in children with profound hearing loss fitted with a device at a young age: part II-Content of the first lexicon. Ear and Hearing, 30(5), 541-551.

Oh, S., Park, H., \& Lee, E. (2015). Characteristics of iconic gesture comprehension and production in late-talkers. Communication Sciences \& Disorders, 20(2), 266-276.

Pae, S. (1993). Early vocabulary in Korean: Are nouns easier to learn than verbs?

(Doctoral dissertation). University of Kansas, Lawrence, USA.
Pae, S., \& Kwak, K. (2011). Korean MacArthur-Bates Communicative Development Inventories (K M-B CDI). Seoul; Mindpress.

Preston, J., Frost, S., Mencl, W., Fulbright, R., Landi, N., Grigorenko, E., ..., \& Pugh, K. (2010). Early and late talkers: school-age language, literacy and neurolinguistic differences. Brain, 133(8), 2185-2195.

Rescorla, L. (1989). The language development survey. Journal of Speech and Hearing Disorders, 54(4), 587-599.

Rescorla, L., \& Achenbach, T. (2002). Use of the Language Development Survey (LDS) in a national probability sample of children 18 to 35 months old. Journal of Speech, Language, and Hearing Research, 45(4), 733-743.

Rescorla, L., \& Alley, A. (2001). Validation of the Language Development Survey (LDS). Journal of Speech, Language, and Hearing Research, 44(2), 434-445.

Rescorla, L., Hadicke-Wiley, M., \& Escarce, E. (1993). Epidemiological investigation of expressive language delay at age two. First Language, 13(37), $5-22$.

Rescorla, L., Lee, Y., Oh, K., \& Kim, Y. (2013). Lexical development in Korean: vocabulary size, lexical composition, and late talking. Journal of Speech, Language, and Hearing Research, 56(2), 735-747.

Rescorla, L., Mirak, J., \& Singh, L. (2000). Vocabulary growth in late talkers: Lexical development from 2;0 to 3;0. Journal of Child Language, 27(2), 293311.

Robertson, S. B., \& Ellis-Weismer, S. (1999). Effects of treatment on linguistic and social skills in toddlers with delayed language development. Journal of Speech, Language, and Hearing Research, 42(5), 1234-1248.

Taylor, M., \& Gelman, S. A. (1988). Adjectives and nouns: children's strategies for learning new words. Child Development, 59(2), 411-419.

Tardif, T., Shatz, M., \& Naigles, L. (1997). Caregiver speech and children's use of nouns versus verbs: a comparison of English, Italian, and Mandarin. Journal of Child Language, 24(3), 535-565.

Tomasello, M. (2000). Do young children have adult syntactic competence?. Cognition, 74(3), 209-253.

Xuan, L., \& Dollaghan, C. (2013). Language-specific noun bias: evidence from bilingual children. Journal of Child Language, 40(5), 1057.

Zubrick, S., Taylor, C., Rice, M., \& Slegers, D. (2007). Late language emergence at 24 months: an epidemiological study of prevalence, predictors, and covariates. Journal of Speech, Language, and Hearing Research, 50(6), 1562-1592. 


\section{국문초록}

\section{8-36개월 말 늦은 아동과 생활연령 및 표현어휘능력이 일치하는 일반 아동의 초기 어휘발달의 차이}

임동선 ${ }^{1} \cdot$ 양윤희 ${ }^{2} \cdot$ 최정원 ${ }^{1} \cdot$ 한지아 ${ }^{1} \cdot$ 채미선 ${ }^{1}$

${ }^{1}$ 이화여자대학교 대학원 언어병리학과, ${ }^{2}$ 이화여자대학교 특수교육연구소

배경 및 목적: 본 연구에서는 18-36개월의 말 늦은 아동, 생활연령을 일치시킨 일반아동, 그리고 표현어휘를 일치시킨 일반아동의 초기 어휘발달의 양상과 두 단어 조합의 예측인자를 확인하고자 하였다. 방법: 25-36개월의 말 늦은 아동(LT) 43 명, 생활연령을 일치시킨 일 반 아동(AM) 847 명, 그리고 언어연령을 일치시킨 $18-24$ 개월의 일반 아동(VM) 161 명, 총 1,051 명의 아동의 데이터가 사용되었다. 본 연 구에서는 워드뱅크(wordbank.stanford.edu)를 통해 데이터를 얻어 분석하였다. 결과: 각 집단의 두 단어 조합 양상에 유의한 차이가 있 었다. AM 집단 내에서 두 단어 조합을 자주 산출하는 아동은 $12.6 \%, \mathrm{LT}$ 집단은 $4.7 \%, \mathrm{VM}$ 집단은 $0.6 \%$ 를 보였다. 두 단어 조합에 대해

서는 AM 집단에서만 표현어휘, 수용어휘, 명사가 유의한 설명력을 보이는 것으로 나타났다. 논의 및 결론: LT 집단은 더 어린 VM 집단 보다 더 많은 두 단어 조합 산출을 보였으며, 이는 두 단어 조합에 대해 연령 효과를 무시할 수 없음을 보여준다. 품사별 산출과 관련하여 명사 산출은 동사, 형용사에 비해 가장 높았고, 명사, 동사, 형용사에서 모두 AM 집단이 가장 높은 단어 산출을 보였다. LT, VM 집단의 두 단어 조합에 기여하는 요인은 불분명하나, AM 집단의 경우 표현어휘, 수용어휘, 명사 등이 유의한 기여를 할 수 있는 것으로 보인다.

핵심어: $\mathrm{K} \mathrm{M-B} \mathrm{CDI,} \mathrm{18-36개월} \mathrm{아동,} \mathrm{말} \mathrm{늦은} \mathrm{아동,} \mathrm{초기} \mathrm{어휘발달,} \mathrm{두} \mathrm{단어} \mathrm{조합}$

본 연구는 2019년 한국연구재단 국제협력사업의 지원을 받아 수행되었음(NRF-2019K2A9A2A20109497).

\section{참고문헌}

김명순, 이가현 (2009). 어린이집에서 24-36 개월 영아-교사간 공동주의와 영아의 어휘력간의 관계. 아동학회지, 30(5), 155-165.

배소영, 곽금주 (2011). 한국판 맥아더-베이츠 의사소통 발달평가(K MB CDI). 서울: 마인드프레스.

오선주, 박현주, 이은주 (2015). 말 늦은 아동의 도상적 제스처 이해 및 표현 특성. Communication Sciences \& Disorders, 20(2), 266-276.

이민정, 임동선 (2020). 5개월 추적연구를 통한 말 늦은 아동의 표현어휘 발달 예측 요인. 특수교육, 19(1), 5-28.

이윤경, 김영태 (2003). 단순언어장애 아동들의 낱말산출 능력: 명사와 동사를 중심으로. 언어청각장애연구, 8(1), 1-19.

이희란 (2009). 초기 동사 발달과 언어적 입력의 영향: 종결어미의 소통기능을 중심으로. 언어치료연구, 18(1), 1-15.

이희란, 장유경, 최유리, 이승복 (2008). 부모보고를 통해 종단관찰한 한국 아동의 초기 문법형태소 습득. 언어청각장애연구, 13(2), 159-173.

장유경 (2004). 한국 영아의 초기 어휘발달: 18개월-36개월. 한국심리학회지: 발달, 17(4), 91-105.

장유경, 배소영 (2003). Noun versus Verb Bias Revisited. 음성과학, 10(1), 131-142.

조수정, 황민아, 최경순 (2014). 말 늦은 아동의 문장 이해 전략. 말소리와 음성과학, 6(3), 13-21.

조윤희, 이현진 (2004). 한국 아동의 형용사 습득에서 비교와 어휘적 정보의 역할. 한국심리학회지: 발달, 17(2), 197-212.

최은희, 서상규, 배소영. (2001). 1; 1-2;6 세 한국 아동의 표현어휘 연구. 언어청각장애연구, 6(1), 1-16.

하승희, 설아영, 소성민, 배소영 (2016). 자발화 분석을 통한 만 2세 한국아동의 말-언어발달 특성. Communication Sciences \& Disorders, 21(1), 47-

59.

\section{ORCID}

임동선(제1저자, 교신저자, 교수 https://orcid.org/0000-0001-8254-9504); 양윤희(공동저자, 박사후연구원 https://orcid.org/0000-0003-3240-5996); 최정원(공동저자, 대학원생 https://orcid.org/0000-0002-5609-6553); 한지아(공동저자, 대학원생 https://orcid.org/0000-0002-2563-0944);

채미선(공동저자, 대학원생 https://orcid.org/0000-0003-2570-2204) 